\title{
The End of World
} Population Growth

Wolfgang Lutz, Warren Sanderson, and Sergei Scherbov

RR-01-12

October 2001 


\title{
The End of World Population Growth
}

\author{
Wolfgang Lutz \\ International Institute for Applied Systems Analysis \\ Warren Sanderson \\ International Institute for Applied Systems Analysis \\ and State University of New York at Stony Brook, USA \\ Sergei Scherbov \\ University of Groningen, The Netherlands
}

RR-01-12

October 2001

Reprinted from Nature, 412:543-545 (2001).

International Institute for Applied Systems Analysis - Schlossplatz 1 - A-2361 Laxenburg - Austria Tel: (+43 2236) 807 • Fax: (+43 2236) 71313 • E-mail: publications@iiasa.ac.at • Web: www.iiasa.ac.at 
Research Reports, which record research conducted at IIASA, are independently reviewed before publication. Views or opinions expressed herein do not necessarily represent those of the Institute, its National Member Organizations, or other organizations supporting the work.

Reprinted with permission from Nature, 412:543-545 (2001).

Copyright (c) 2001 Macmillan Magazines Ltd.

All rights reserved. No part of this publication may be reproduced or transmitted in any form or by any means, electronic or mechanical, including photocopy, recording, or any information storage or retrieval system, without permission in writing from the copyright holder. 


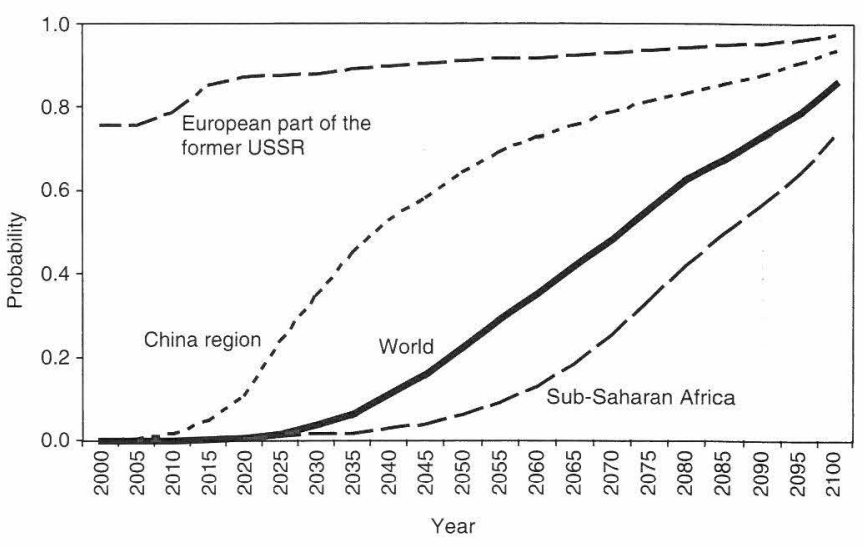

Figure 1 Forecasted probability that population will start to decline at or before the indicated date.

\title{
The end of world population growth
}

\author{
Wolfgang Lutz ${ }^{\star}$, Warren Sanderson ${ }^{\star}$ \& Sergei Scherbov $\ddagger$ \\ * International Institute for Applied Systems Analysis, Schlossplatz 1, \\ A-2361 Laxenburg, Austria \\ $\dagger$ Departments of Economics and History, State University of New York at \\ Stony Brook, New York 11794-4384, USA \\ $\mp$ University of Groningen, PO Box 800, NL-9700 AV Groningen, The Netherlands
}

There has been enormous concern about the consequences of human population growth for the environment and for social and economic development. But this growth is likely to come to an end in the foreseeable future. Improving on earlier methods of probabilistic forecasting ${ }^{1}$, here we show that there is around an 85 per cent chance that the world's population will stop growing before the end of the century. There is a 60 per cent probability that the world's population will not exceed 10 billion people before 2100 , and around a 15 per cent probability that the world's population at the end of the century will be lower than it is today. For different regions, the date and size of the peak population will vary considerably.

Figure 1 shows the probability that the world population size would reach a peak at or before any given year. It indicates that there is around a 20 per cent chance that the peak population would be reached by 2050 , around a 55 per cent chance that it would be reached by 2075 , and around an 85 per cent chance that it would be reached by the end of the century.

There is around a 75 per cent chance that the peak population of the European portion of the former USSR has already been reached in 2000 , an 88 per cent probability that it will be reached by 2025 , and over a 95 per cent chance by the end of the century. For the China region, the probability of reaching a peak within the next two decades is still low owing to its relatively young age structure. By 2040 the probability becomes greater than half. In sub-Saharan Africa, despite the prevalence of HIV, there is a low probability of peaking before the middle of the century. The probability reaches 25 per cent by 2070,50 per cent by 2085, and almost 75 per cent by 2100 , owing to assumed reductions in fertility.

Figure 2 shows the distribution of simulated world population sizes over time. The median value of our projections reaches a peak around 2070 at 9.0 billion people and then slowly decreases. In 2100 ,

the median value of our projections is 8.4 billion people with the 80 per cent prediction interval bounded by 5.6 and 12.1 billion. The medium scenario of the most recent United Nations long-range projection ${ }^{2}$ is inserted in Fig. 2 as a white line. It is almost identical to our median until the middle of the century, but is higher thereafter owing to the United Nations assumption of universal replacement-level fertility, that is two surviving children per woman.

Table 1 shows the median population sizes and associated 80 per cent prediction intervals for the world and its 13 regions, indicating major regional differences in the paths of population growth. While over the next two decades the medians are already declining in eastern Europe and the European portion of the former Soviet Union, the populations of north Africa and sub-Saharan Africa are likely to double, even when we take into account the uncertainty about future HIV trends.

The China region and the South Asia region, which have approximately the same population size in 2000, are likely to follow very different trends. Owing to an earlier fertility decline, the China region is likely to have around 700 million fewer people than the South Asia region by the middle of the century. This absolute difference in population size is likely to be maintained over the entire second half of the century and illustrates the strong impact of the timing of fertility decline on eventual population size ${ }^{3}$.

Our findings concerning the timing of the end of world population growth are robust to plausible changes in parameter assumptions. A detailed sensitivity analysis is provided as Supplementary Information. The forecasts of the World Bank, the US Census Bureau, and the medium variant of the United Nations ${ }^{2,4,5}$ are based on independent assumptions; the median trajectory of our world forecasts is almost identical to these up until 2045. Of these three forecasts, only the UN long-range projections provide scenarios of the world's population to the end of the century. If we define the end of population growth slightly less literally, and take it to correspond with annual population growth of one-tenth of one per cent or less, the United Nations medium projection also shows the end of population growth during the second half of the century. Their medium scenario predicts that world population growth will first fall below one-tenth of one per cent at around 2075.

A stabilized or shrinking population will be a much older population. At the global level the proportion above age 60 is likely to increase from its current level of 10 per cent to around 22 per cent in 2050. This is higher than it is in western Europe today. By the end of the century it will increase to around 34 per cent, and extensive population ageing will occur in all world regions. The most extreme levels will be reached in the Pacific OECD (mostly Japan), where half of the population is likely to be age 60 and above by the end of the century, with the 80 per cent uncertainty interval 



\section{supplementary information}

\section{Supplementary Information for "The end of world population growth" Nature, V412, 543}

\section{Documentation and Sensitivity Analyses}

The central finding of this study is that there is a high probability that the world's population growth will come to an end in this century. In Section 1, we state the statistical model that we use. In Section 2, we discuss different possible correlations (autocorrelation, correlations between deviations in fertility and life expectancy and correlations across regions) and show the results of sensitivity analyses and their implications on our central finding. In Section 3 we deal with the issue of possible baseline errors in both the size of the starting population and the starting level of fertility.

\section{The Statistical Model}

It is accepted procedure to create population forecasts from an initial distribution of the population by age and sex and forecasts of total fertility rates (TFR), life expectancies at birth, and net migration. Probabilistic population forecasts differ from deterministic forecasts in that they deal with the uncertainty of the course of future rates and therefore must specify future total fertility rates, life expectancies, and net migration as distributions and not as points. Distributions can also be used to deal with other uncertainties such as those relating to the base population size.

In order to generate the required distributions, let $v$ be the total fertility rate, the change in life expectancy at birth, or net migration to be forecasted for periods 1 through $T$ and $v_{t}$ be its forecasted value at time $t$. We express $v_{t}$ as the sum of two terms, its mean at time $t, \bar{\nu}_{t}$ and its deviation from the mean at time $t, \varepsilon_{t}$. In other words, $\nu_{t}=\bar{v}_{t}+\varepsilon_{t}$. The $\bar{\nu}_{t}$ are chosen based on the arguments given in the text of the paper. The $\varepsilon_{t}$ term is assumed to be a normally distributed random variable with mean zero and standard deviation $\sigma\left(\varepsilon_{t}\right)$. The $\sigma\left(\varepsilon_{t}\right)$ are also based on arguments in the text.

Because of the persistence of the factors represented by the $\varepsilon_{t}$, we would generally expect them to be autocorrelated. One of the most commonly used methods of specifying how the $\varepsilon_{t}$ term evolves over time is the simple autoregressive formation $(\operatorname{AR}(1))$, where $\varepsilon_{t}=\alpha^{\prime} \varepsilon_{t-1}+u_{t}$, where $u_{t}$ is an independently distributed normal random variable with mean zero and standard deviation $\sigma(u)$. Another commonly used method is the moving average formation of order $q$, $\operatorname{MA}(q)$ where $q$ is the number of lagged terms in the moving average. We use the following moving average specification:

$$
\varepsilon_{i}=\sum_{i=0}^{q} \alpha_{i} \cdot u_{t-i}
$$

, where $u_{t-i}$ are independently distributed standard normal random variables. To ensure that the

$$
\alpha_{i}=\frac{\sigma\left(\varepsilon_{i}\right)}{\sqrt{q+1}} \text {. Note that } \varepsilon_{t} \text { depends on } q+1
$$
random terms.

The choice between $\mathrm{AR}(1)$ and $\mathrm{MA}(q)$ does not have to do with estimation, but rather with representation. Data do not exist that would allow the estimation of the parameters of either specification at the regional level required in the paper. Neither is more theoretically correct than the other. Both are just approximations to a far more complex reality. When comparably parameterized, they produce very similar distributions of $\varepsilon_{t}$ (see Figures 1 and 2 ).

The choice between the two, therefore, rests on which more accurately reflects arguments concerning the future. From our perspective, the moving average approach has the advantage that the $\sigma\left(\varepsilon_{t}\right)$ terms appear explicitly making it easier to translate ideas about the future into that specification.

We generate correlated random numbers for each forecast year. Fertility and life expectancy change deviations $\left(\varepsilon_{t}\right)$ from pre-specified mean paths can be correlated across regions or fertility and life expectancy change deviations can be correlated with one another within a region. Suppose that we were interested in $R$ correlated states (regions or vital rates). Let $e_{t}\left(e_{t, 1}, \ldots, e_{t, R}\right)$ be a column vector of the $R$ autocorrelated values of $e$ at time $t$ generated as above, but under the assumption that $\sigma\left(e_{t, j}\right)$ is 1.0. Let $V$ be the assumed variance-covariance matrix for the $R$ states. We call the Cholesky decomposition of $V, C$. We compute a column vector $\varepsilon_{t}\left(\varepsilon_{t, 1}, \ldots, \varepsilon_{t, R}\right)$ from the equation $\varepsilon_{t}=C^{\prime} \cdot e_{t}$. 


\section{Sensitivity Analysis of the Implications of Various Correlations}

The future levels of vital rates that enter the simulations can be correlated in different ways. Most important are (a) the correlations between deviations from assumed average trends in fertility and life expectancy, (b) the autocorrelation of deviations within each series of vital rates and (c) the correlations among the deviations from the average vital rate trends in different world regions.

Since the assumed signs and degrees of correlations do influence the results to varying degrees it is important to explicitly address the issue and discuss the implications for the validity of our central findings.

\section{2.a Correlations Between Fertility and Life Expectancy Deviations}

In our earlier work, ${ }^{1}$ we discussed the impact of two different intraregional correlations over time between fertility deviations and deviations in the change in life expectancy at birth on the assumption of zero correlation both between the deviations in fertility levels and between the deviations in changes in life expectancies across regions. In the terminology of that paper, we considered correlations between fertility and mortality deviations of 0.0 and 1.0 . In the terminology of the current paper, where we consider correlations between total fertility rates deviations and life expectancy change deviations, the correlations are 0.0 and -1.0 . Compared to a correlation of 0.0 , the correlation of 1.0 between fertility and life expectancy change deviations produced relatively small decreases in the means of the world population size distributions and relatively large decreases in the standard deviations. This is because high fertility combined with low life expectancies partially offset each other in terms of population size.

It is difficult to do an empirical analysis of past correlations between fertility and life expectancy deviations for our 13 regions. We did an approximate calculation using United Nations data by taking, where possible, a large country in each of our regions. We took United Nations vital rate assumptions from the 1988 assessment ${ }^{2}$ and used them as the trend and calculated deviations from the trend for 1995-2000 using data from the 2000 assessment. ${ }^{3}$ The thirteen countries are Egypt, Nigeria, China, Indonesia, Japan, Pakistan, Iran, India, Poland, France, Brazil, United States, and Bulgaria. The correlation between deviations in the total fertility rate and life expectancy at birth was 0.259 , which is not statistically significantly different from zero (95 percent level of confidence, two-tailed test). On theoretical grounds there is no clear expectation as to what correlation should be expected in the future. That is why we chose 0.0 , but also performed sensitivity analyses to see how our results would be affected by possible deviations from this assumption.

The sensitivity analysis presented here is at the level of one region, North Africa. This region was chosen because the quality of the demographic data in the region is quite good and because its population has a relatively low probability of reaching a peak within the century. The relatively low probability provides room for both upward and downward movements. If we were to present the results at the world level, we would have somewhat different results depending on the interregional correlations that we chose. Considering a single region allows us to present the effects more clearly. To further simplify matters, we have used only the female population. This, in no way, affects the generality of our findings.

Our results are presented in Table 1 and Figure 3. Table 1 shows the same phenomenon that we observed in our earlier work. The main effect of changing the correlation between fertility and life expectancy is on the variance of the distribution of future population sizes. For example, in 2100 when the correlation is -0.9 the 80 percent prediction interval is 123.6 million people wide, while when it is 0.9 it is 172.9 million people wide.

Figure 3 shows the probability of the female population reaching a peak for each year of the century for five different correlations between fertility and life expectancy, $-0.9,-0.5,0.0,0.5$, and 0.9 and for the 31 term moving average specification. By the end of the century, the five lines are so close to one another that they are barely distinguishable. In 2100 , when the correlation is 0.0 , the probability of the peak population being reached by the end of the century is 75.9 percent. If the correlation was 0.5 , the probability would be 76.2 percent and if it was -0.5 , it would be 74.5 percent. Therefore, if the correlation was somewhere between -0.5 and 0.5 and we supposed it to be 0.0 , the maximum error in the probability of the peak being reached by the end of the century would be 1.4 percentage points. Indeed, if the true correlation was somewhere between -0.9 and 0.9 and we assumed it to be equal to zero, the maximum possible error that we could make in the probability of the peak being reached by the end of the century would be 3 percentage points. The results are similar for all regions.

The dataset with 1,000 simulations for the female population of North Africa for the case of the correlation -0.9 is in the file "nature_dataset_1a.xls." A similar dataset based on the assumption of a correlation of 0.9 is in "nature_dataset_1b.xis."

\section{2.b Autocorrelation}

For clarity, we also consider differences in first-order autocorrelation only for females in North Africa. Figure 4 is similar to Figure 3 except that it assumes zero correlation between fertility and life expectancy change deviations and considers three different numbers of terms in the moving average specification, 21,31 , and 41 . The three lines are 
quite close to one another. The probabilities of reaching a peak by the end of the century are $78.9,75.9$, and 73.3 percent, respectively. In the text, our findings are based on a moving average specification with 31 terms. If the correct specification were somewhere between 21 and 41 terms, the maximum error that we would make in the probability of a peak being reached by the end of the century would be 3 percentage points upwards or 2.6 percentage points downward. A similar clustering occurs when this sensitivity analysis is carried out assuming the other four correlations between fertility and life expectancy change deviations discussed in the previous section. The autocorrelation coefficient for our 31 -term case is 0.9677 .

There are not enough time periods to make a useful empirical analysis of autocorrelation even from United Nations data. Our choice is consistent with Lee ${ }^{4}$ (p. 161), which reports that the first-order correlation for the total fertility rate during the twentieth century in the United States was 0.96 . Further, 31 years is close to the length of a generation and one way of interpreting Lee's finding is that there were influences on fertility that operated on generational scale.

\section{2.c Correlations Across Regions}

Due to rapidly increasing globalisation of medical technology as well as of new threats to life, it is assumed that the interregional correlations of the deviations from the expected trends in life expectancy improvements are very high. For fertility increasing globalisation of media (transmission of norms and fashions with respect to fertility relevant life styles) as well as reproductive technology is also likely to result in high global correlations. But due to the fact that fertility is much more strongly embedded in regional norms, traditions and religions the correlation is assumed to be somewhat lower than in the case of life expectancy.

For the results presented in the main text interregional correlations in the deviations from expected trends were assumed to be 0.9 in the case of life expectancy and 0.7 in the case of fertility. Under these assumptions, the probability that world population growth would come to an end during this century is 86 percent. We did two other computations, one in which the interregional correlation for life expectancy was lowered to 0.7 and the one for fertility was decreased to 0.5 , and another with correlations 0.7 and 0.0 , respectively. The probability that the world's population growth would end by 2100 remains virtually constant in all three cases with differences only visible around the middle of the century (see Figure 5).

Table 2 gives the median world population size and the 80 percent prediction intervals for the years 2000, 2025, 2050, 2075 , and 2100 . The table shows that median world population sizes are hardly affected by changing the correlation structure, but that the 80 percent prediction interval is. For example, in 2100 the 80 percent prediction interval for the interregional fertility correlation of 0.7 and the interregional life expectancy correlation of 0.9 is 6.54 billion people. In the case of fertility correlation of 0.0 and life expectancy correlation of 0.7 , the 80 percent prediction interval is only 4.03 billion people wide. But as shown above, this does not significantly affect the probability of world population peaking by the end of this century.

The dataset incorporating 2,000 simulations at intervals of five years for our base case with interregional fertility correlation of 0.7 and interregional life expectancy correlation of 0.9 appears in file "nature_dataset_2.xls."

\section{Baseline Errors}

Errors in the baseline data of a population projection are a significant source of error of the projected population especially in the nearer term future. In the longer run errors in the assumed trends dominate. The analysis of these issues in the U.S. National Research Council (NRC) report, ${ }^{5}$ which was based on earlier important work by Alho ${ }^{6}$ and Keilman, ${ }^{7}$ has recently been further developed by Bulatao ${ }^{8}$ who distinguishes between the errors in the baseline population size, the errors in the assumed starting levels in fertility and mortality and the errors due to wrong assumption on the trends. His decomposition of the errors for selected UN and World Bank forecasts since 1973 attributes a smaller proportion of the total error to baseline errors than the NRC report did. Studying the errors at different levels of regional aggregation he concludes that world errors tend to be much smaller than the error for the average country because country errors have tended to offset.

What do these findings from past projections imply for the uncertainty ranges of future population trends presented here? In the following we will discuss (a) the sensitivity of assumed serious errors in the baseline population on our main results and (b) how assumed changes in the starting level of fertility (using the recently announced UN projections ${ }^{3}$ as an example) impact our main conclusion.

\section{3a. Errors in Baseline Population Size}

We did calculations assuming that the true population of sub-Saharan Africa in 2000 was 5 percent and 10 percent higher than our figure. These are very high baseline errors for a world region by any standards. The consequence of this was that the probability of the world's population reaching a peak by 2100 was reduced by one-tenth of one percentage point (for both the 5 and 10 percent changes). The mean of the world's population distribution would be around 173 million people or roughly 2 percent higher in 2100 than we forecast, if the true population of sub-Saharan Africa in 2000 were 10 percent higher than our figure. The effect of an error in initial population size will be larger in 
sub-Saharan Africa than in other regions because of the still rapid population growth there. In the opposite case of overestimating the population of Sub-Saharan Africa in 2000 , the probability of world population growth ending during this century would be slightly higher than our figure. This sensitivity analysis shows that plausible errors in initial population sizes will have virtually no impact on our conclusion that the world population growth is likely to end in the current century.

\section{3b. Errors in Baseline Total Fertility Rates}

By using the recently released $\mathrm{UN}^{3}$ population forecasts we can assess the effects of plausible changes in baseline total fertility estimates. Between 1999 and 2001 the UN has reassessed its estimates of fertility levels for 1995-2000 and increased fertility figures for some large countries in sub-Saharan Africa and South Asia. This change in baseline fertility is one of the sources (along with changed assumptions about trends) of an increase in projected world population sizes from $U N^{9}$ (1999) to $U N^{3}$ (2001).

Here we study the sensitivity of our findings to the changed UN baseline fertility assumptions. Our results are presented in Tables 3 and 4, where we utilise all the assumptions in our paper, except that we adjust our total fertility rates in the initial year according to the differences in estimates of 1995-2000 fertility between UN ${ }^{9}(1999)$ and UN ${ }^{3}$ (2001). In Table 3, we show the probability of a peak in population size being reached for the world and for our 13 regions for 25 -year intervals from 2000 to 2100 using both total fertility rate sets as starting values. Using the higher total fertility rates, the probability that the world's population would peak during the century is 85.7 percent, compared to 86.0 percent using our original total fertility rates. The effect of this plausible increase in baseline total fertility rates has a negligible effect on the probability of reaching a peak in all regions of the world as shown in Table 3.

Table 4 shows the median population size and 80 percent prediction interval for the world's population and the population of our 13 regions by 25 -year intervals from 2000 to 2100 . It is the analogue of Table 1 in the main text but based on higher initial total fertility rates. Using the lower total fertility rates, the world's median population size in 2100 is 8.41 billion with an 80 percent prediction interval between 5.58 and 12.12 billion people. With the higher total fertility rates, the world's median population size in 2100 is 8.45 billion with an 80 percent prediction interval between 5.57 and 12.22 billion. It is clear that adjusting the baseline total fertility rates higher has little effect on the distribution of future world population sizes in 2100 .

\section{Conclusion}

The main finding of our paper is that there is a high probability, around 85 percent, that the population of the world will reach a peak sometime during the current century. We have considered the sensitivity of this finding to a number of uncertain parameters. The evidence strongly supports the conclusion that our main finding is not sensitive to plausible changes in those parameters.

\section{References}

1. Lutz, W., Sanderson, W. \& Scherbov, S. Probabilistic population projections based on expert opinion. In The Future Population of the World: What Can We Assume Today? (ed. Lutz, W.) 397-385 (Earthscan, London, rev. ed., 1996).

2. United Nations. World Population Prospects 1988 (United Nations, New York, ST/ESASER.A/106, 1989).

3. United Nations. 2000 Assessment (United Nations, New York, 2001). Web site http://www.un.org/esa/population.

4. Lee, R. D. Probabilistic approaches to population forecasting. In Frontiers of Population Forecasting (eds. Lutz, W., Vaupel, J. W. \& Ahlburg, D. A.), a supplement to Population and Development Review 24 (1998), 156-190 (1999).

5. Bongaarts, J. \& Bulatao, R. A., Eds, Beyond Six Billion. Forecasting the World's Population. (National Academy Press, Washington, DC, 2000).

6. Alho, J. M. The magnitude of error due to different vital processes in population forecasts. International Journal of Forecasting 8, 301-314 (1992).

7. Keilman, N. How accurate are the United Nations world population projections? In Frontiers of Population Forecasting (eds. Lutz, W., Vaupel, J. W. \& Ahlburg, D. A.), a supplement to Population and Development Review 24 (1998), 15-41 (1999).

8. Bulatao, R. A. Visible and Invisible Sources of Error in World Population Projections. Paper presented at the Annual Meeting of the Population Association of America, Washington, DC, 29-31 March 2001.

9. United Nations. Long-Range World Population Projections: Based on the 1998 Revision (United Nations, New York, ESAJP/WP.153, 1999). 


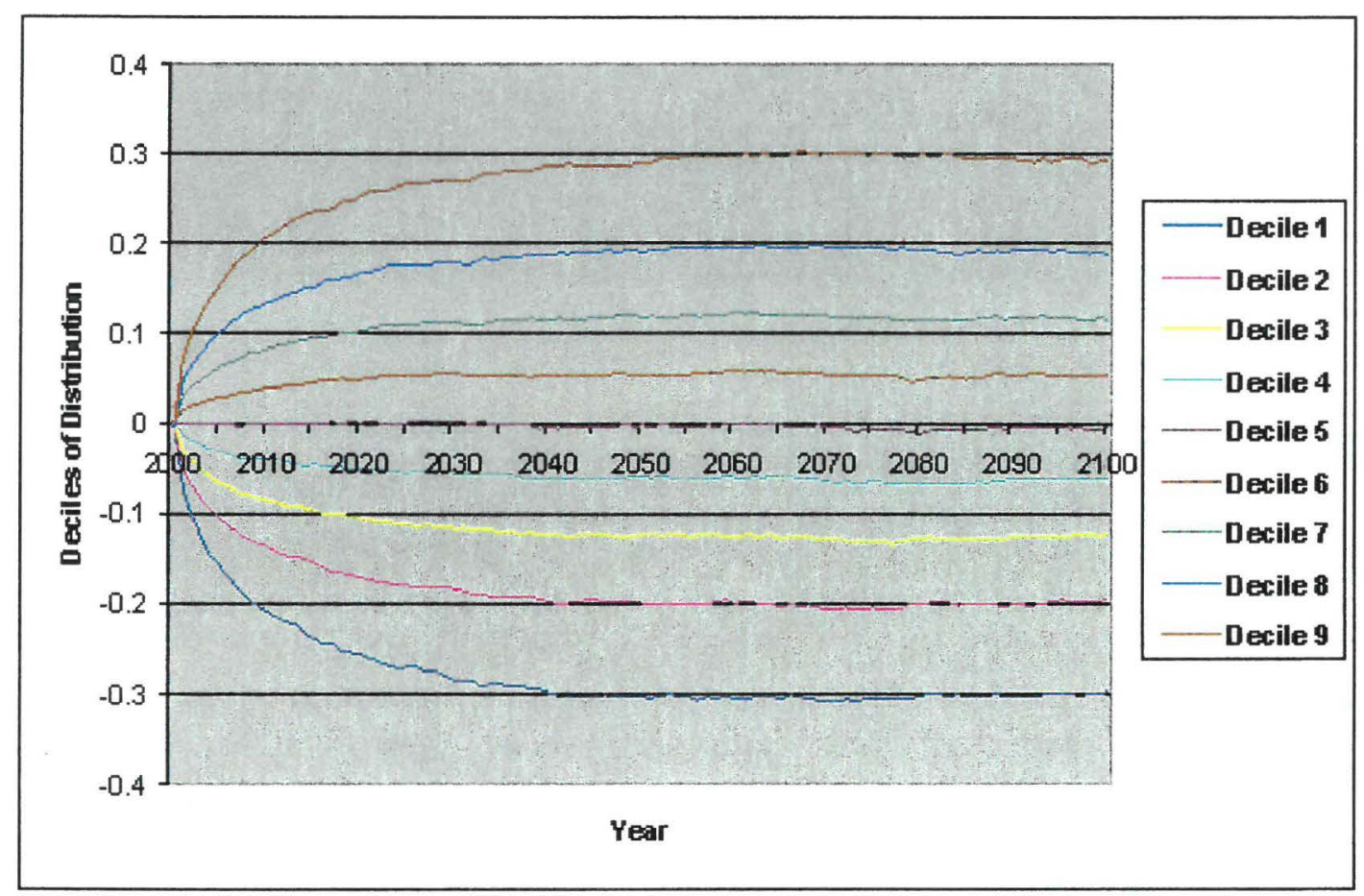

Figure 1. $A R(1), \alpha=0.9677, \sigma(u)=0.05896, v(0)=0,10,000$ simulations.

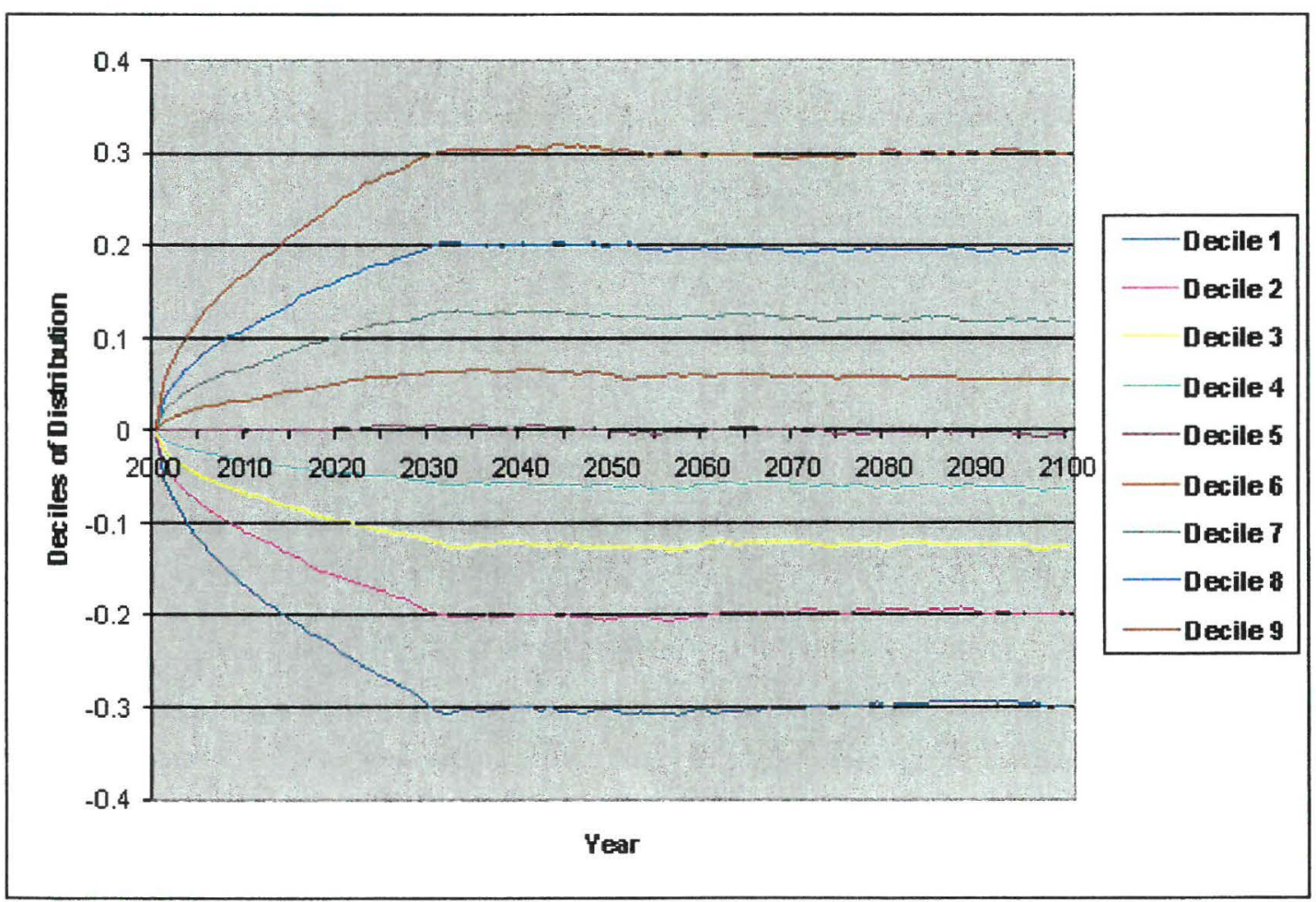

Figure 2. $\mathrm{MA}(30)$ (31 terms), $\sigma\left(\varepsilon_{t}\right)=0.234,31$ initial values of $u=0,10,000$ simulations. 


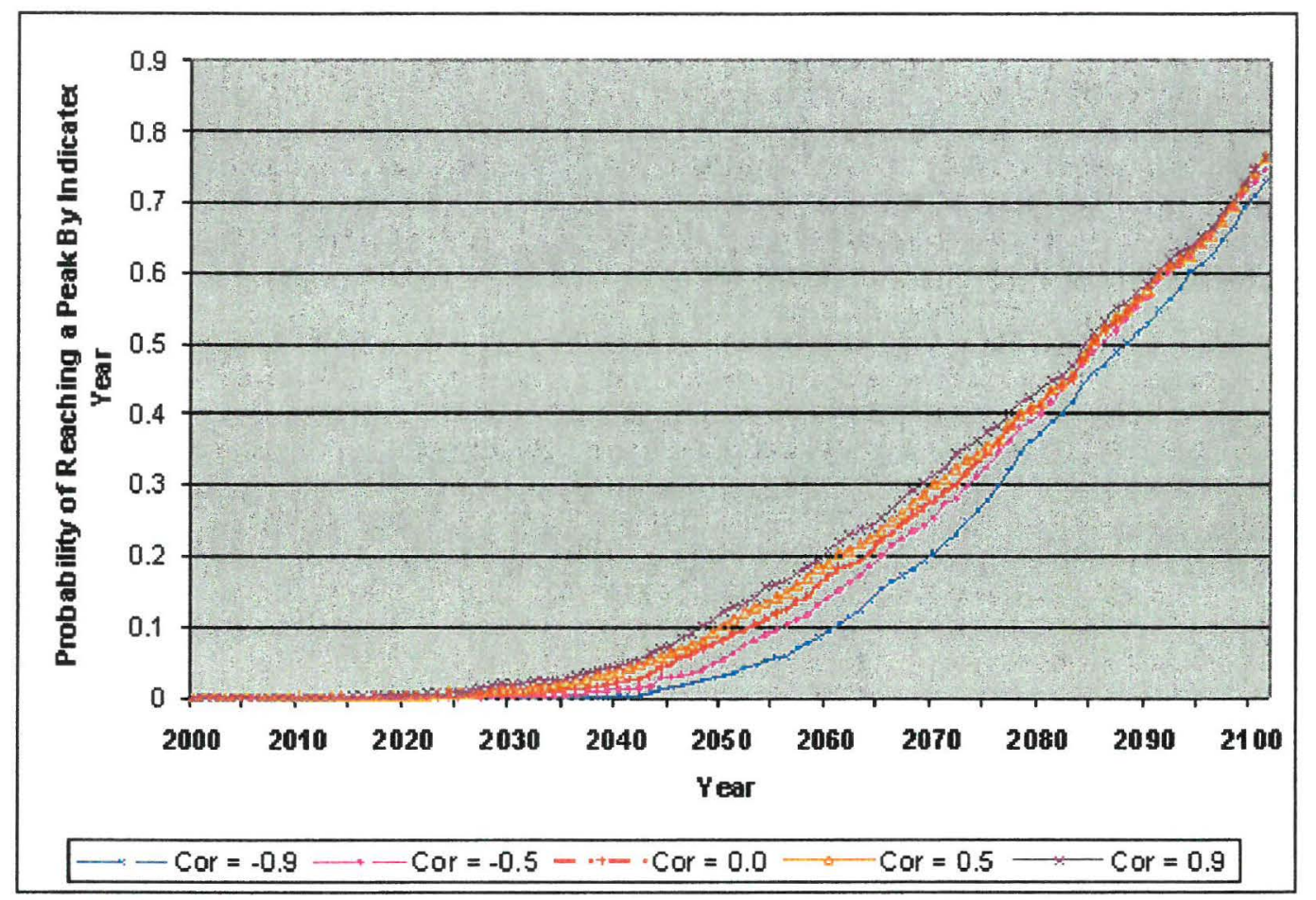

Figure 3. Probability of the female population of North Africa reaching a peak by indicated year using 31-term moving average specification for correlations between total fertility rate of female life expectancy at birth of $-0.9,-0.5,0.0,0.5$, and 0.9 .

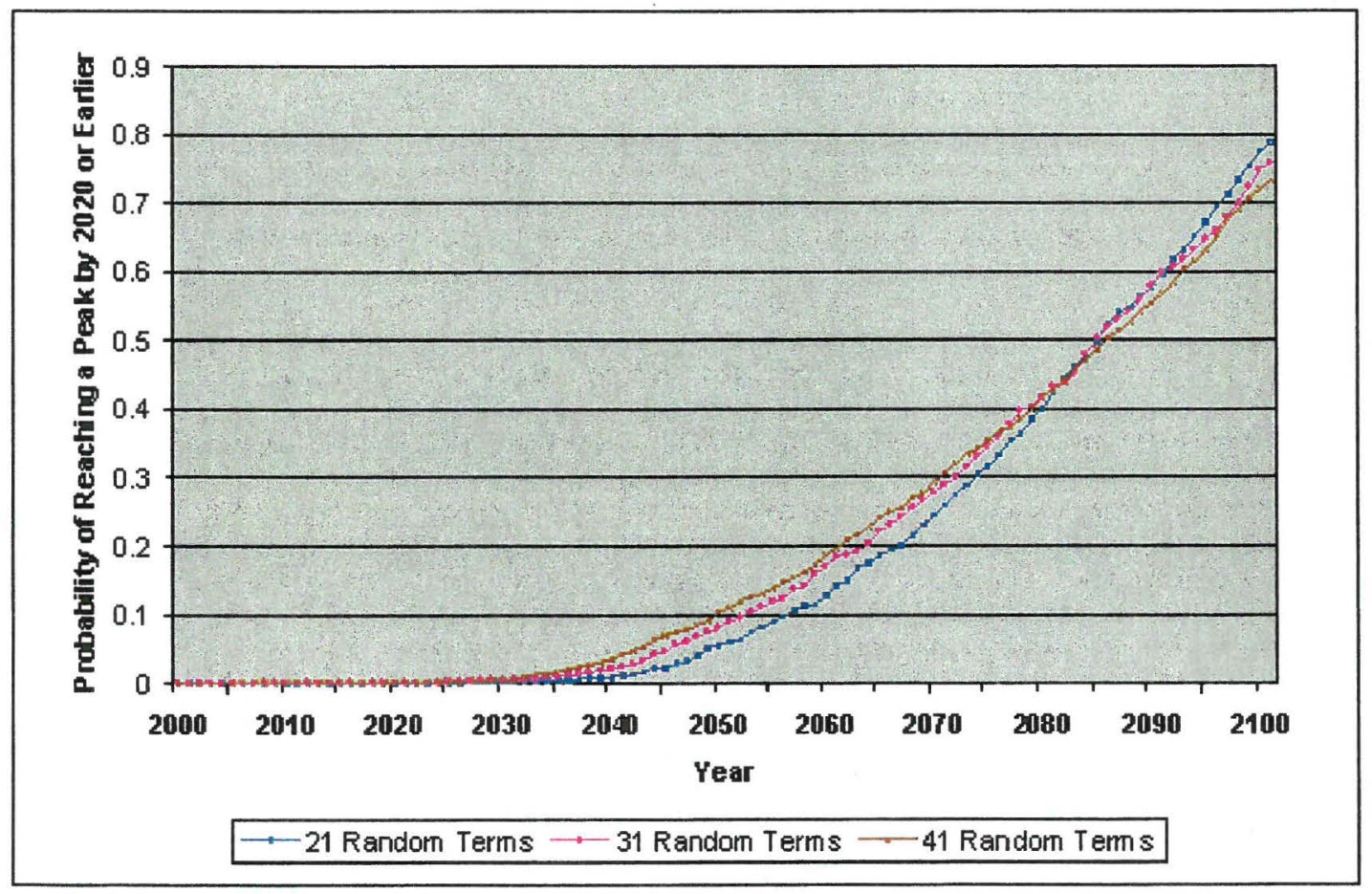

Figure 4. Probability of the female population of North Africa reaching a peak by indicated year using correlation of 0.0 between total fertility rate and female life expectancy at birth for moving average specifications of 21,31 , and 41 terms 


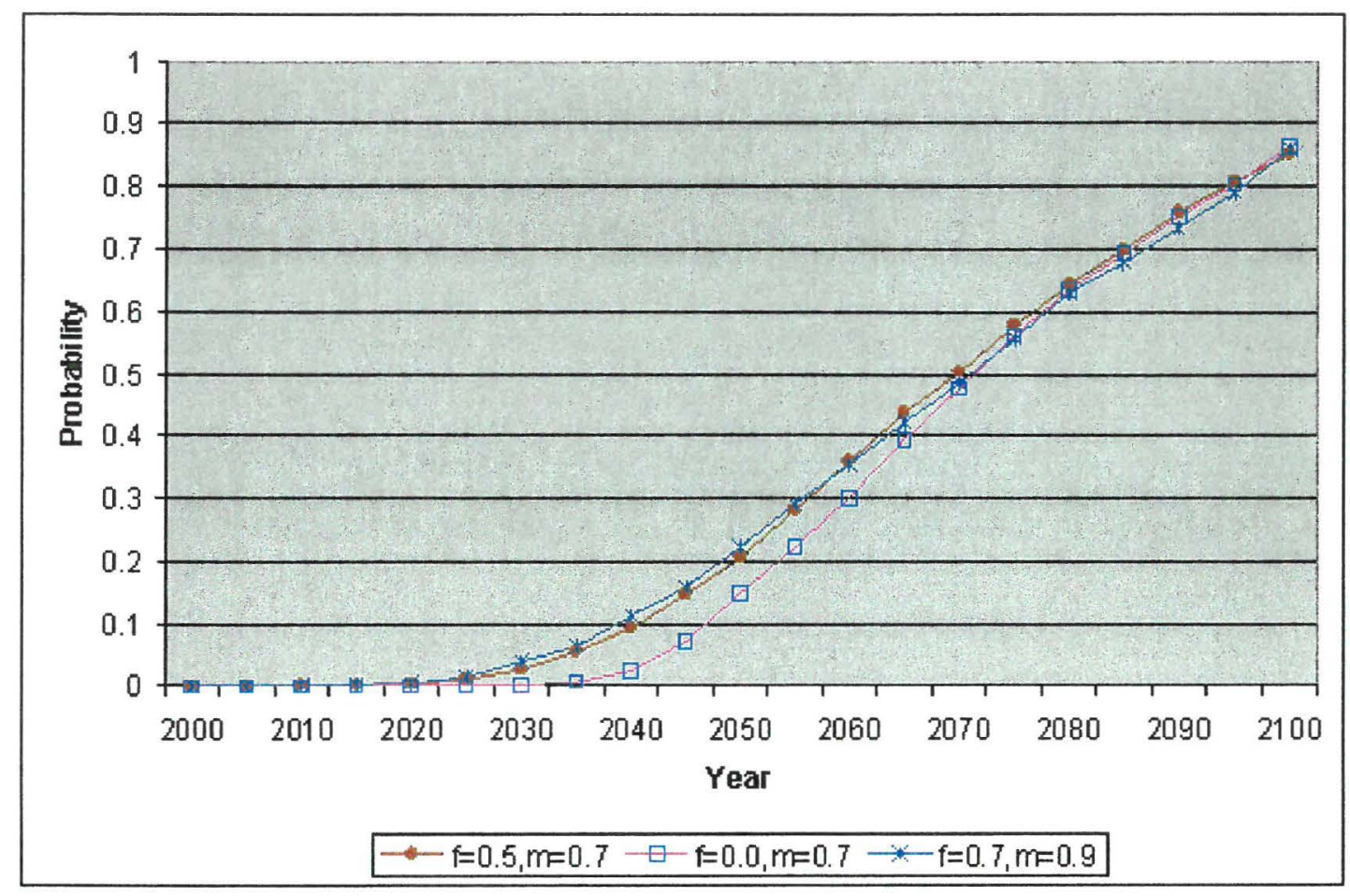

Figure 5. Probability that the peak in population size is reached before the indicated date for three different

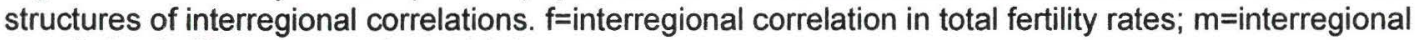
correlation in life expectancies at birth.

Table 1. Median and 80 percent prediction interval (in parentheses) for the female population of North Africa, 31-term moving average specification, correlations of deviations from average paths of the total fertility rate and changes in female life expectancy at birth of $-0.9,0.0$, and 0.9 .

\begin{tabular}{|c|c|c|c|c|c|}
\hline $\begin{array}{l}\text { Fertility - Life } \\
\text { Expectancy } \\
\text { Deviation } \\
\text { Correlation }\end{array}$ & 2000 & 2025 & 2050 & 2075 & 2100 \\
\hline-0.9 & 85.8 & $\begin{array}{l}129.5 \\
(116.3-141.7)\end{array}$ & $\begin{array}{l}160.9 \\
(133.1-187.9)\end{array}$ & $\begin{array}{l}178.6 \\
(132.7-224.3)\end{array}$ & $\begin{array}{l}174.3 \\
(119.3-242.9)\end{array}$ \\
\hline 0.0 & 85.8 & $\begin{array}{l}129.0 \\
(114.6-144.2)\end{array}$ & $\begin{array}{l}161.1 \\
(127.7-196.5)\end{array}$ & $\begin{array}{l}177.3 \\
(122.9-235.4)\end{array}$ & $\begin{array}{l}176.3 \\
(107.8-260.5)\end{array}$ \\
\hline 0.9 & 85.8 & $\begin{array}{l}129.8 \\
(113.2-145.4)\end{array}$ & $\begin{array}{l}160.1 \\
(126.2-202.1)\end{array}$ & $\begin{array}{l}174.4 \\
(117.6-247.0)\end{array}$ & $\begin{array}{l}175.0 \\
(100.9-273.8)\end{array}$ \\
\hline
\end{tabular}


Table 2. Median world population size and 80 percent prediction intervals (in parentheses) for three sets of interregional correlations of deviations from average paths of total fertility rates and changes in life expectancies at birth.

\begin{tabular}{llllll}
\hline & 2000 & 2025 & 2050 & 2075 & 2100 \\
\hline $\begin{array}{l}\text { Fertility Corr. }=0.7, \\
\text { Life Exp. Corr. }=0.9\end{array}$ & 6.06 & $\begin{array}{l}7.83 \\
(7.22-8.46)\end{array}$ & $\begin{array}{l}8.80 \\
(7.35-10.44)\end{array}$ & $\begin{array}{l}8.95 \\
(6.64-11.65)\end{array}$ & $\begin{array}{l}8.41 \\
(5.58-12.12)\end{array}$ \\
$\begin{array}{l}\text { Fertility Corr. }=0.5, \\
\text { Life Exp. Corr. }=0.7\end{array}$ & 6.06 & $\begin{array}{l}7.80 \\
(7.23-8.38)\end{array}$ & $\begin{array}{l}8.78 \\
(7.41-10.20)\end{array}$ & $\begin{array}{l}(6.83 \\
(6.78-11.22)\end{array}$ & $\begin{array}{l}(5.35 \\
(5.73-11.42)\end{array}$ \\
$\begin{array}{l}\text { Fertility Corr. }=0.0, \\
\text { Life Exp. Corr. }=0.7\end{array}$ & 6.06 & $\begin{array}{l}7.80 \\
(7.46-8.16)\end{array}$ & $\begin{array}{l}8.78 \\
(7.97-9.71)\end{array}$ & 8.89 & $(7.45-10.49)$ \\
\hline
\end{tabular}

Table 3. Probability that population will reach a peak before the given date using total fertility rates based on the assumptions used in the text and those with higher baseline fertility following the UN ${ }^{3}(2001)$ assessment.

\begin{tabular}{|c|c|c|c|c|}
\hline \multirow[b]{2}{*}{ Region } & \multicolumn{2}{|l|}{2075} & \multicolumn{2}{|l|}{2100} \\
\hline & $\begin{array}{l}\text { TFR } \\
\text { Used in paper }\end{array}$ & $\begin{array}{l}\text { TFR } \\
\text { Higher baseline } \\
\text { fertility }\end{array}$ & $\begin{array}{l}\text { TFR } \\
\text { Used in paper }\end{array}$ & $\begin{array}{l}\text { TFR } \\
\text { Higher baseline } \\
\text { fertility }\end{array}$ \\
\hline World & 0.557 & 0.557 & 0.860 & 0.857 \\
\hline $\begin{array}{l}\text { European Former } \\
\text { Soviet Union }\end{array}$ & 0.935 & 0.949 & 0.973 & 0.979 \\
\hline Eastern Europe & 0.928 & 0.933 & 0.972 & 0.972 \\
\hline Western Europe & 0.782 & 0.777 & 0.939 & 0.935 \\
\hline Pacific OECD & 0.839 & 0.837 & 0.959 & 0.957 \\
\hline Pacific Asia & 0.592 & 0.588 & 0.869 & 0.866 \\
\hline China Region & 0.814 & 0.810 & 0.937 & 0.932 \\
\hline South Asia & 0.681 & 0.680 & 0.924 & 0.923 \\
\hline Middle East & 0.313 & 0.323 & 0.715 & 0.712 \\
\hline Central Asia & 0.379 & 0.382 & 0.754 & 0.751 \\
\hline Latin America & 0.324 & 0.324 & 0.666 & 0.659 \\
\hline North America & 0.367 & 0.373 & 0.703 & 0.699 \\
\hline Sub-Saharan Africa & 0.337 & 0.339 & 0.734 & 0.729 \\
\hline North Africa & 0.363 & 0.385 & 0.753 & 0.750 \\
\hline
\end{tabular}


Table 4. Median population sizes and 80 percent prediction intervals (in parentheses) using all the same assumptions as Table 1 in the main text but with total fertility adjusted upwards according to the differences between $\mathrm{UN}^{9}(1999)$ and $\mathrm{UN}^{3}$ (2001).

\begin{tabular}{|c|c|c|c|c|c|}
\hline Region & 2000 & 2025 & 2050 & 2075 & 2100 \\
\hline $\begin{array}{l}\text { World } \\
\text { [billions] }\end{array}$ & 6.06 & $\begin{array}{l}7.86 \\
(7.23-8.50)\end{array}$ & $\begin{array}{l}8.84 \\
(7.36-10.50)\end{array}$ & $\begin{array}{l}9.00 \\
(6.65-11.71)\end{array}$ & $\begin{array}{l}8.45 \\
(5.57-12.22)\end{array}$ \\
\hline $\begin{array}{l}\text { European Former } \\
\text { Soviet Union } \\
\text { [millions] }\end{array}$ & 235.64 & $\begin{array}{l}215.45 \\
(199.26-231.07)\end{array}$ & $\begin{array}{l}182.28 \\
(148.57-219.53)\end{array}$ & $\begin{array}{l}152.35 \\
(104.33-209.96)\end{array}$ & $\begin{array}{l}134.13 \\
(79.63-209.97)\end{array}$ \\
\hline $\begin{array}{l}\text { Eastern Europe } \\
\text { [millions] }\end{array}$ & 121.19 & $\begin{array}{l}116.54 \\
(108.12-124.58)\end{array}$ & $\begin{array}{l}102.56 \\
(84.54-123.01)\end{array}$ & $\begin{array}{l}85.24 \\
(59.17-117.17)\end{array}$ & $\begin{array}{l}72.94 \\
(42.54-113.65)\end{array}$ \\
\hline $\begin{array}{l}\text { Western Europe } \\
\text { [millions] }\end{array}$ & 455.63 & $\begin{array}{l}477.86 \\
445.30-509.51)\end{array}$ & $\begin{array}{l}470.37 \\
(398.55-551.28)\end{array}$ & $\begin{array}{l}434.10 \\
(321.26-563.53)\end{array}$ & $\begin{array}{l}391.10 \\
(255.75-569.63)\end{array}$ \\
\hline $\begin{array}{l}\text { Pacific OECD } \\
\text { [millions] }\end{array}$ & 149.93 & $\begin{array}{l}154.70 \\
(143.61-165.58)\end{array}$ & $\begin{array}{l}148.40 \\
(124.42-174.50)\end{array}$ & $\begin{array}{l}135.38 \\
(99.70-175.83)\end{array}$ & $\begin{array}{l}122.45 \\
(78.54-172.50)\end{array}$ \\
\hline $\begin{array}{l}\text { Pacific Asia } \\
\text { [millions] }\end{array}$ & 476.43 & $\begin{array}{l}626.34 \\
(568.23-683.40)\end{array}$ & $\begin{array}{l}701.60 \\
(573.37-844.29)\end{array}$ & $\begin{array}{l}702.05 \\
(507.59-938.20)\end{array}$ & $\begin{array}{l}652.33 \\
(407.92-947.95)\end{array}$ \\
\hline $\begin{array}{l}\text { China Region } \\
\text { [billions] }\end{array}$ & 1.41 & $\begin{array}{l}1.61 \\
(1.49-1.72)\end{array}$ & $\begin{array}{l}1.58 \\
(1.30-1.86)\end{array}$ & $\begin{array}{l}1.42 \\
(1.00-1.89)\end{array}$ & $\begin{array}{l}1.25 \\
(0.76-1.88)\end{array}$ \\
\hline $\begin{array}{l}\text { South Asia } \\
\text { [billions] }\end{array}$ & 1.37 & $\begin{array}{l}1.95 \\
(1.74-2.16)\end{array}$ & $\begin{array}{l}2.26 \\
(1.80-2.79)\end{array}$ & $\begin{array}{l}2.25 \\
(1.54-3.10)\end{array}$ & $\begin{array}{l}1.97 \\
(1.19-3.04)\end{array}$ \\
\hline $\begin{array}{l}\text { Middle East } \\
\text { [millions] }\end{array}$ & 172.12 & $\begin{array}{l}284.60 \\
(251.38-317.63)\end{array}$ & $\begin{array}{l}367.39 \\
(299.58-443.60)\end{array}$ & $\begin{array}{l}411.97 \\
(294.99-541.89)\end{array}$ & $\begin{array}{l}410.02 \\
(258.15-592.87)\end{array}$ \\
\hline $\begin{array}{l}\text { Central Asia } \\
\text { [millions] }\end{array}$ & 55.88 & $\begin{array}{l}81.28 \\
(72.65-90.01)\end{array}$ & $\begin{array}{l}99.64 \\
(79.31-120.96)\end{array}$ & $\begin{array}{l}106.82 \\
(75.20-144.89)\end{array}$ & $\begin{array}{l}105.42 \\
(65.73-159.17)\end{array}$ \\
\hline $\begin{array}{l}\text { Latin America } \\
\text { [millions] }\end{array}$ & 515.27 & $\begin{array}{l}708.86 \\
(641.17-776.57)\end{array}$ & $\begin{array}{l}840.11 \\
(677.68-1006.83)\end{array}$ & $\begin{array}{l}904.47 \\
(644.97-1202.10)\end{array}$ & $\begin{array}{l}933.11 \\
(583.87-1385.09)\end{array}$ \\
\hline $\begin{array}{l}\text { North America } \\
\text { [millions] }\end{array}$ & 313.67 & $\begin{array}{l}379.54 \\
(350.77-410.72)\end{array}$ & $\begin{array}{l}422.46 \\
(357.84-498.40)\end{array}$ & $\begin{array}{l}440.46 \\
(342.93-566.49)\end{array}$ & $\begin{array}{l}452.61 \\
(311.39-630.19)\end{array}$ \\
\hline $\begin{array}{l}\text { Sub-Saharan } \\
\text { Africa } \\
\text { [millions] }\end{array}$ & 611.19 & $\begin{array}{l}1000.76 \\
(874.92-1126.09)\end{array}$ & $\begin{array}{l}1358.10 \\
(1039.89- \\
1747.53)\end{array}$ & $\begin{array}{l}1569.20 \\
(1058.01- \\
2253.84)\end{array}$ & $\begin{array}{l}1542.84 \\
(901.33-2515.01)\end{array}$ \\
\hline $\begin{array}{l}\text { North Africa } \\
\text { [millions] }\end{array}$ & 173.26 & $\begin{array}{l}253.49 \\
(224.62-281.40)\end{array}$ & $\begin{array}{l}305.07 \\
(243.26-372.08)\end{array}$ & $\begin{array}{l}327.05 \\
(231.14-434.54)\end{array}$ & $\begin{array}{l}323.90 \\
(207.67-471.19)\end{array}$ \\
\hline
\end{tabular}




\section{Ordering Information}

Orders must include the publication number and should be sent to the Publications Department, International Institute for Applied Systems Analysis, A-2361 Laxenburg, Austria.

Telephone: +432236807

Telefax: +43223671313

E-mail:molina@iiasa.ac.at

A full list of IIASA publications is available at www.iiasa.ac.at 
$\rightleftharpoons$ International Institute for Applied Systems Analysis Schlossplatz 1, A-2361 Laxenburg, Austria

$\checkmark$ Tel: +432236807 Fax: +43223671313

I I AS A www.iiasa.ac.at 